\title{
Effectiveness of the Comprehensive Childhood Protection System for vulnerable mothers and children ${ }^{1}$
}

\author{
Estela $\operatorname{Arcos}^{2}$ \\ Luz Angélica Muñoz ${ }^{3}$ \\ Ximena Sanchez ${ }^{4}$ \\ Antonia Vollrath ${ }^{5}$ \\ Patricia Gazmuri ${ }^{5}$ \\ Margarita Baeza ${ }^{6}$
}

\begin{abstract}
Objectives: to establish the effectiveness of the public benefits and services of the "Chile Grows with You" and "Protect Network" programs for socially vulnerable women and children in an urban community in the Metropolitan Region of Chile. method: Descriptive study employing a questionnaire. The sample consisted of 132 mothers and their 133 infants, all grouped according to social vulnerability. Primary data were collected via a structured interview of the mothers and were complemented with institutional (secondary) data. Descriptive and associative analyses were performed. Results: the perception of social vulnerability by the professionals was low at the time of admission into the program. The effectiveness of the universal and specific benefits was low, with better results for the children than for the mothers. However, no significant differences were observed according to vulnerability. Another finding was the low access to specific benefits for children with psychosocial risk and psychomotor delay, especially in the most vulnerable group. Conclusion: the results revealed a gap in the access to the benefits guaranteed by law. To overcome this situation, nurses must strengthen their skills in contextualized health practices and the comprehensive administration of interdisciplinary and intersectoral networks.
\end{abstract}

Descriptors: Public Policy; Delivery of Health Care; Social Vulnerability; Child Health; Nursing.

\footnotetext{
${ }^{1}$ Supported by Vicerrectoria de Investigacion y Doctorado, Universidad Andrés Bello, process \# DI-21-10/R.

2 MSc, Full Professor, Facultad de Enfermería, Universidad Andrés Bello, Santiago, Chile.

${ }^{3} \mathrm{PhD}$, Full Professor, Facultad de Enfermería, Universidad Andrés Bello, Santiago, Chile.

${ }^{4}$ MSc, Full Professor, Facultad de Ciencias Sociales, Universidad de Playa Ancha, Santiago, Chile.

${ }_{5}^{5} \mathrm{MSc}$, Asistant Professor, Facultad de Enfermería, Universidad Andrés Bello, Santiago, Chile.

${ }^{6} \mathrm{MSc}$, Doctoral student, Facultad de Enfermería, Universidad Andrés Bello, Santiago,Chile.
}

Corresponding Author:

Estela Arcos

Universidad Andres Bello. Facultad de Enfermería

Av. República, 237

26618476, Santiago, Chile

E-mail: marcos@unab.cl 


\section{Introduction}

The Chilean subsystem of social protection for vulnerable children comprises a set of benefits and actions that are guaranteed by law and performed by various state institutions and agents, which include product measurements related to the coverage, focus, and quality of social benefits ${ }^{(1)}$. The aim is to safeguard early childhood development, especially in children exposed to social determinants such as low educational levels in the parents, dysfunctional families, precarious employment, maternal depression, domestic violence, disorganized-avoidant attachment, and lack of encouragement ${ }^{(2-5)}$.

Analysis from the perspective of social, economic, cultural, and political determinants has elucidated the mechanism underlying disease-causing processes, which are produced independently of universal access to health systems ${ }^{(6-9)}$. Much evidence indicates the following: a) the social and economic circumstances of individuals and groups influence their health as much as or more so than health care and b) social determinants are the best predictors of the health status and the individual and collective lifestyle. Moreover, it has been reported that the social determinants of health are unevenly distributed among the population and interact with each other in complex ways throughout life, thereby determining the differential distribution of health conditions that are manifested as disparities and inequalities ${ }^{(2-4,7,10-12)}$.

Social factors fall outside the health system and must be addressed in a holistic manner to ensure the best possible start in life for children. In this context, social practice in nursing is crucial for this discipline's relevant assigned role within societies that exhibit deep structural inequalities. This goal means ensuring the right of access to the benefits of social policy, which has the essential purpose of mitigating the negative impact of the context in child development and welfare(2,13-16).

In Chile, public policy for social protection offers fairness from the outset via the program "Chile Grows with You" (ChCC, for its initials in Spanish), which employs an integrated range of services that promote motherhood and secure attachment, effective communication, and healthy guidelines for parenting as its major components ${ }^{(17-18)}$. The program is applied from conception up to 4 years of age and includes all infants from $40 \%$ of the poorest and most vulnerable households and families, or those individuals with special needs. The policy has been designed with consideration of the guaranteed universal rights perspective, in which the family, community, and social network are at the heart of child development. Regarding the institutions and working teams of the involved sectors, this integration of social protection policies has designated them as responsible for managing the implementation, financing, provision, and regulation of access to the services offered, which is a condition that requires contextualized response capabilities and new methods of institutional organization(18-20).

Consequently, the nursing profession is driven by necessity to reflect on a proactive health practice to ensure the quality, relevance, comprehensiveness, and effectiveness of public policy management in reducing equity gaps, particularly in the most vulnerable child populations with concentrated inequality ${ }^{(21)}$. In relation to this fact, we may ask, what is the effectiveness of accessing the publicly offered benefits from "Chile Grows with You" and associated programs for vulnerable children and women? To answer this question, a descriptive study was conducted to establish the effectiveness of the public offering of benefits and/or services of the "Chile Grows with You" and "Protect Network" (Red Protege) programs for socially vulnerable children and women in an urban community of the Metropolitan Region of Chile.

The present study is justified by the importance of obtaining empirical data that will contribute to the improved implementation of the program under consideration, thus redirecting social policy in the area and enhancing the relevance of social practice in the nursing profession in the context of child health programs.

\section{Methods}

The type of study was a descriptive study to establish the behavior of a set of variables considered relevant to the investigation. The technique used involved a social survey. The study sample consisted of 1,514 women (plus their neonates from live births) who attended health centers in the public network of an urban community in the Metropolitan Region of the country, which was assigned to the "Chile Grows with You" program in 2009. The subjects were classified as socially vulnerable according to criteria established by the Ministry of Planning (MIDEPLAN, for its initials in Spanish) and scored $\leq 11,734$ points on the Social Protection Card (FPS, for its initials in Spanish) application. The subjects with scores $\leq 11,734$ points were stratified into three groups: extreme vulnerability $(\leq 4,213$ points), moderate vulnerability $(4,214-8,500$ points), and low vulnerability (8,501-11,734 points). 
A stratified sampling design with a proportional distribution was used to accurately represent the characteristics of the population and to ensure the inclusion of the elements in each layer, which are homogeneous within the stratum and heterogeneous outside the stratum, based on the social vulnerability score. The sample size was estimated using a maximum variance assumption and confidence level of $95 \%$ and estimated errors of $0.076(7.6 \%)$ at the level of the entire population; $0.105(10.5 \%)$ at stratum level $1 ; 0.133(13.3 \%)$ at stratum level 2, and 0.186 at stratum level 3. During the fieldwork, due to outdated and inaccurate addresses, some units of analysis were replaced from the health centers' records, thus retaining the stratum sampling procedures.

The instrument of measurement was applied to 132 women. The unit of analysis was the dyad (motherchild), with the mother supplying the information. One of the women gave birth to twins.

The following factors were used to characterize the population: 1) individual variables of the woman and infant, including the biosociodemographic history and 2) biomedical and psychosocial conditions identified during the prenatal care, the birth care, and the woman's and child's health care. Information was collected regarding the mother's age, marital status, educational level, type of gainful employment, social security contributions, social insurance, household headship, psychosocial risks, disabilities, and gestational age at entry into the "Chile Grows with You" program. Information was also gathered regarding the child's weight, height, sex, Apgar at the $1^{\text {st }}$ and $5^{\text {th }}$ minutes, gestational age at birth, disabilities, morbidity, developmental lag, psychomotor retardation, abuse, and social vulnerability. In addition, background data were collected regarding the subjects, their relationship to the caregivers, and the presence of the parents at home. This information was obtained from the interview and subsequently completed via consultation with secondary sources such as the healthcare record card, the "Chile Grows with You" record card, and the Social Protection record card.

The effectiveness of the access to benefits and/ or services was based on characterization of the variables on the universal benefits for the woman and her child, specific benefits received when the woman and child met a condition defined by the "Chile Grows with You" program regulations, and integrated services when the woman met the access conditions defined by the regulations of the other associated social network programs.
Sources of information: primary information was obtained through structured interviews of the mothers. To confirm any information that the mother did not remember exactly, secondary data were obtained from the "Chile Grows with You" program records, the Social Protection Card, and the maternal and child healthcontrol notebooks. Permission to review the medical records was not granted.

Instrument: The structured interview included the following: a) 38 questions regarding the biosociodemographic history of the woman and child, as well as background information on psychosocial risk; b) 47 questions regarding access to the specific and comprehensive universal benefits that were received by the woman and child from the "Chile Grows with You" program and associated programs during the prenatal, delivery, postnatal, neonatal, and childhood periods.

The validity of the measurement instrument was established by content analysis or construct validity, which established the relationship of the questions to the background of the study's frame of reference. The content validity was complemented by expert judgment; two experts were asked to review the questions to establish their relevance, based on the conceptual and methodological background provided by the research team.

From September 2011 to January 2012, the researchers collected the data via a direct interview of the mothers, either at the health centers or at home. To control the bias of the interviews outside the home, a sheltered and private space was made available in the health centers. The mothers' participation was voluntary, and they made the decision when the project's objectives and procedures were explained to them. The participants signed a consent form that guaranteed privacy and confidentiality. The study was approved by the Ethics Committee of the School of Nursing (registration \# L1/CECENF/14) and was authorized by the Municipal Corporation of Social Development.

The raw and refined databases were configured using SPSS and Excel computer software for the data processing and analysis. Analyses were performed using descriptive positions and scatter statistics, according to the type of variable. The Chi-square test and/or Fisher exact test were employed to establish comparisons, associations, differences, and correlations, and an analysis of variance (ANOVA) was used to compare the variance, with a significance level of $p<0.05$. 


\section{Results}

The background information of the dyads revealed a higher proportion of adverse determinants in the groups with extreme and moderate social vulnerability, although the differences were not significant $(p \geq 0.05)$. One in two women was single, with less than 12 years of schooling $(50.0 \%, 40.9 \%$, and $33.4 \%$ in the extreme -, moderate -, and low-vulnerability groups, respectively), and one in three women had gainful employment. The social security and health insurance benefits did not amount to $100 \%$ coverage in the three groups.

The neonates/infants with extreme and moderate vulnerabilities had higher incidences of low birth weight $(8.5 \%$ and $9.3 \%$, respectively), prematurity $(11.3 \%, 9.1 \%$, and $5.6 \%$, respectively), developmental delay ( $11.3 \%$ and $6.8 \%$, respectively) and developmental lag (16.9\% and $9.1 \%$, respectively). In one out of every two to three children, the parent was present in the home $(p \geq 0.05)$. Exclusive breastfeeding lasted longer than six months, particularly in the extremely vulnerable group $(87.5 \%, 77.3 \%$, and $50.0 \%, \mathrm{p}<0.05)$. In all three groups, there was early entry into and good compliance with the child health control, which is a favorable factor in terms of obtaining benefits from the "Chile Grows with You" program $(p \geq 0.05)$.

Many medical and psychosocial risks were observed in the dyads, with a more unfavorable situation in the group with extreme vulnerability $(p \geq 0.05)$. These factors included mental health problems, conflicts regarding motherhood, substance abuse, and gender-based violence in the mothers. Their children lived in family environments with a high incidence of mental health problems, domestic violence, drug abuse, and unsafe childcare (Table 1). There was a low perception of the social vulnerability of the dyads by the professionals at entry to control, which is a situation that hides the vulnerability.

Table 1 - Background information regarding the biomedical condition, psychosocial risk, and psychosocial-risk etiology in the neonates/infants and their mothers, based on the social vulnerability score of the Social Protection Card

\begin{tabular}{|c|c|c|c|c|c|c|c|}
\hline \multirow{3}{*}{ Risks } & \multirow{3}{*}{ Presence } & \multicolumn{6}{|c|}{ Social Vulnerability } \\
\hline & & \multicolumn{2}{|c|}{ Extreme } & \multicolumn{2}{|c|}{ Moderate } & \multicolumn{2}{|c|}{ Low } \\
\hline & & $\mathbf{N}$ & $\%$ & $\mathbf{N}$ & $\%$ & $\mathbf{N}$ & $\%$ \\
\hline \multicolumn{8}{|l|}{ Neonates/infants } \\
\hline Biomedical risk* & Yes & 21 & 29.6 & 10 & 22.7 & 2 & 11.1 \\
\hline Psychosocial risk* & Yes & 33 & 46.5 & 12 & 27.3 & 7 & 38.9 \\
\hline Social-vulnerability detection ${ }^{\dagger}$ & Yes & 13 & 18.3 & 11 & 25.0 & 3 & 16.7 \\
\hline \multicolumn{8}{|l|}{ Causes of psychosocial risk } \\
\hline Family environment / mental health & Yes & 22 & 66.7 & 9 & 75.0 & 3 & 42.9 \\
\hline Domestic violence & Yes & 10 & 30.3 & 3 & 25.0 & 2 & 28.6 \\
\hline Substance abuse & Yes & 9 & 27.3 & 3 & 25.0 & 0 & 0.0 \\
\hline Child-care conditions & Yes & 8 & 24.2 & 4 & 33.3 & 0 & 0.0 \\
\hline Habitability & Yes & 7 & 21.2 & 3 & 25.0 & 0 & 0.0 \\
\hline Health and hygiene & Yes & 7 & 21.2 & 2 & 16.7 & 2 & 28.6 \\
\hline Environmental safety & Yes & 5 & 15.2 & 2 & 16.7 & 0 & 0.0 \\
\hline Child abuse & Yes & 1 & 3.0 & 0 & 0.0 & 0 & 0.0 \\
\hline \multicolumn{8}{|l|}{ Mothers } \\
\hline Biomedical risk* & Yes & 25 & 35.7 & 22 & 50.0 & 10 & 55.6 \\
\hline Psychosocial risk ${ }^{*}$ & Yes & 34 & 49.3 & 18 & 40.9 & 8 & 44.4 \\
\hline Social-vulnerability detection ${ }^{\star \dagger}$ & Yes & 17 & 24.3 & 6 & 13.6 & 2 & 11.1 \\
\hline \multicolumn{8}{|l|}{ Causes of psychosocial risk } \\
\hline Depressive symptoms & Yes & 10 & 29.4 & 6 & 33.3 & 2 & 25.0 \\
\hline Conflicts regarding motherhood & Yes & 10 & 29.4 & 3 & 16.7 & 1 & 12.5 \\
\hline Substance abuse & Yes & 6 & 17.6 & 5 & 27.7 & 3 & 37.5 \\
\hline Gender violence & Yes & 5 & 14.7 & 3 & 16.7 & 1 & 12.5 \\
\hline Pregnancy during adolescence & Yes & 4 & 11.8 & 1 & 5.6 & 1 & 12.5 \\
\hline
\end{tabular}

* No significant differences, $\mathrm{p} \geq 0.05$

† Vulnerability detection was performed by the professional who provided entry into the "Chile Grows with You" program. 
The effectiveness of the transfer of universal benefits/ services in the dyad was not $100 \%$, with better results in the children $(66.1 \% ; 69.5 \%$, and $58.7 \%$, respectively, $\mathrm{p} \geq$ $0.05)$ than in their mothers $(55.8 \%, 54.2 \%$, and $54.8 \%$, respectively, $p \geq 0.05$ ) (Figure 1 ). The effectiveness of specific services was low (less than 30\%), particularly in the neonates/infants. A slightly better situation was found for the mothers $(34.7 \%, 37.2 \%$, and $38.8 \%$, respectively, $\mathrm{p} \geq 0.05$ ) (Figure 1 ).

Universal $\quad \square$ Specific

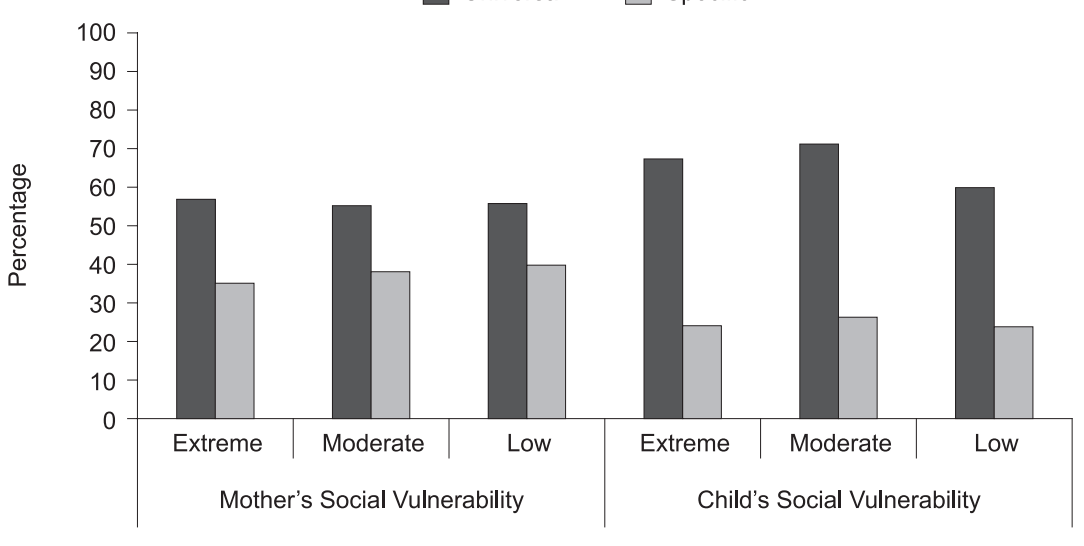

No significant differences, $p \geq 0.05$

Figure 1 - Transfer ratio of universal and specific benefits from the Comprehensive Protection System ("Chile Grows with You") that were effectively received by the mothers and their neonates/infants, according to the social vulnerability

The critical point for the transfer of universal benefits was the low participation in educational workshops that provided resources to strengthen motherhood and secure attachment $(31.4 \%, 22.7 \%$, and $27.8 \%$, respectively, $\mathrm{p} \geq 0.05$ ), the purpose of which was to support healthy lifestyles during the pregnancy and birth and to promote parental and family involvement to ensure a secure bond with the unborn child.

The neonates/infants also underwent a low transfer of benefits for parenting support because only one in two mothers in the three groups participated in the educational workshops, thus experiencing only partial delivery of materials for guiding the child development.

If the "Chile Grows with You" program was organized around the most vulnerable children, then the effectiveness observed in the universal and specific transfers in dyads with psychosocial risk did not reflect that intention. Reality showed that the access varied from $57.1 \%$ to $73.8 \%$ for universal benefits and from $18 \%$ to $22 \%$ for specific benefits for children ( $p \geq 0.05$. In mothers at psychosocial risk, the access to universal benefits did not exceed $60 \%$ (40\% for specific benefits); however, the women's situation was still better than that of their children $p \geq 0.05$ (Figure 2 ).
More disturbing was the situation of children who were diagnosed with developmental delay and/ or developmental lag, for whom the universal benefits achieved a maximum effectiveness of $78.6 \%$ and $26.7 \%$ for the specific benefits. The situation was worst for the children who displayed delayed psychomotor development and were part of the most vulnerable group (Figure 3).

Another critical point for the delivery of specific services was the social support provided by the teams of the psychosocial programs and social network programs, especially for mental health problems, violence, drug addiction, and conflicts regarding motherhood. The children exhibited defenselessness because the care management was not focused on the groups with exposures to adverse determinants; consequently, there was less opportunity to correct problems in child development.

Finally, the effectiveness of comprehensive services for the mother was insufficient in that very few women had the opportunity to improve their educational level, employment status, or treatment for mental health problems and family dysfunction (Table 2). Only $4.8 \%$ of mothers with extreme vulnerability reported being included in the "Chile in Solidarity" (Chile Solidario) program. 


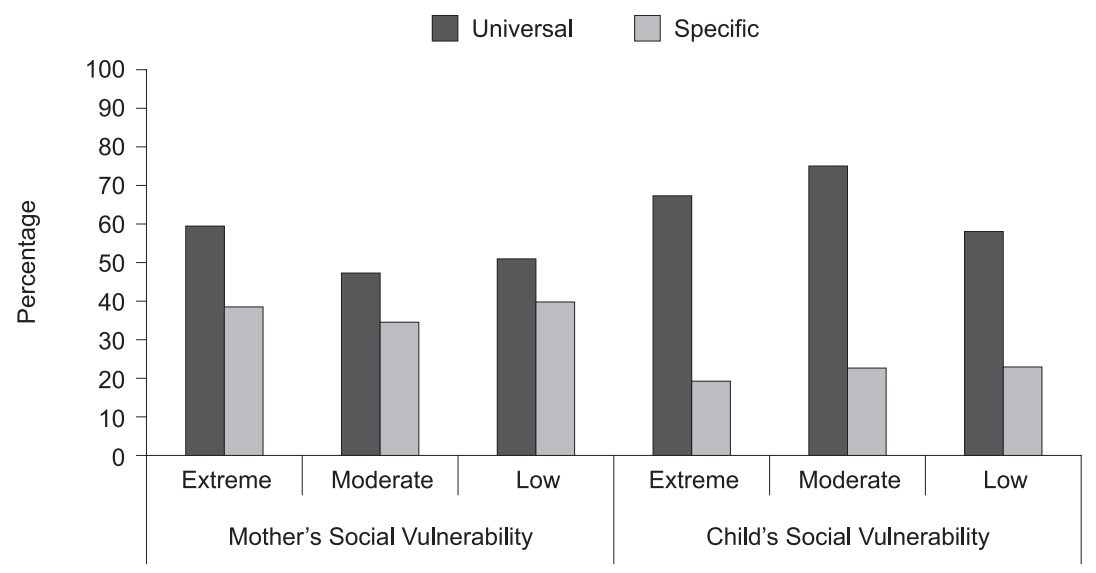

Psychosocial risk

No significant differences, $p \geq 0.05$

Figure 2 - Transfer ratio of the universal and specific benefits from the Comprehensive Protection System ("Chile Grows with You") that were effectively received by the mothers and neonates/infants at psychosocial risk, according to the social vulnerability

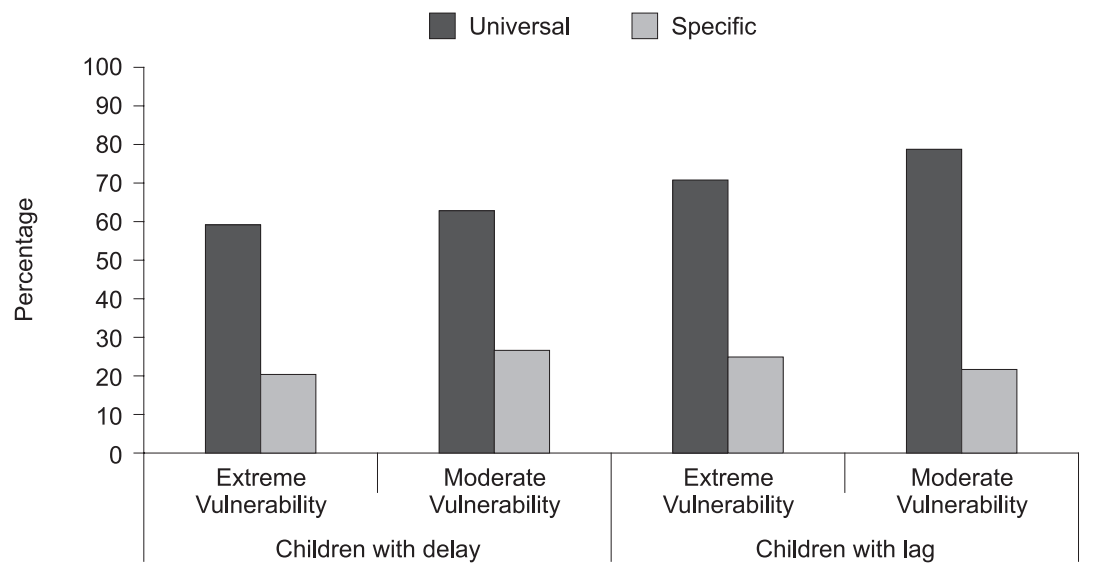

Figure 3 - Transfer ratio of the universal and specific benefits from the Comprehensive Protection System ("Chile Grows with You") that were effectively received by the mothers and their neonates/infants with developmental delay or developmental lag, according to the social vulnerability

Table 2 - Comprehensive benefits transferred to the mothers with the conditions listed below, according to the social vulnerability score of the Social Protection Card (2009)

\begin{tabular}{|c|c|c|c|c|c|c|c|}
\hline \multirow{3}{*}{ Comprehensive benefits } & \multirow{3}{*}{ Transferred } & \multicolumn{6}{|c|}{ Social Vulnerability } \\
\hline & & \multicolumn{2}{|c|}{ Extreme } & \multicolumn{2}{|c|}{ Moderate } & \multicolumn{2}{|c|}{ Low } \\
\hline & & $\mathbf{N}$ & $\%$ & $\mathbf{N}$ & $\%$ & $\mathbf{N}$ & $\%$ \\
\hline Remedial education & Yes & 3 & 9.4 & 1 & 6.3 & 0 & 0.0 \\
\hline Employment access & Yes & 7 & 21.2 & 1 & 5.3 & 0 & 0.0 \\
\hline Mental-health assistance & Yes & 11 & 36.7 & 7 & 58.3 & 1 & 12.5 \\
\hline Family dysfunction assistance & Yes & 3 & 14.3 & 0 & 0.0 & 0 & 0.0 \\
\hline Legal assistance & Yes & 2 & 50.0 & 0 & 0.0 & & \\
\hline Family-violence assistance & Yes & 0 & 0.0 & 0 & 0.0 & 0 & 0.0 \\
\hline Access to the "Chile in Solidarity" program & Yes & 3 & 4.8 & & & & \\
\hline
\end{tabular}




\section{Discussion}

Countries with high levels of inequality, as in the case of Chile, must incorporate public policies for social protection to address poverty and the generated vulnerability(18-20). The results of the present study demonstrated the precarious living conditions of the mothers and children, as well as the gap between the expected and observed results from the access to the benefits and/or services guaranteed by law ${ }^{(1)}$.

Although the children and their mothers were admitted early and displayed good compliance with the health controls and although the professionals applied screening protocols for risks and psychosocial problems, there was no timely and focused management to ensure the access to preventive health services and the protection of comprehensive development in all of the children and women at psychosocial risk, as has been recommended in the reviewed literature(18-21). This fact is relevant because the "Chile Grows with You" program offers a range of services beginning with pregnancy and because the purpose of these services is to encourage early emotional ties between the children and their primary caregivers, thereby building a parental framework in which a secure attachment is essential for each stage of child development ${ }^{(3)}$. Insufficient focus on the delivery of services to children at psychosocial risk is an indicator of the invisibility of management by nursing professionals in the articulation of the social, family, and community networks as support systems for reinforcing and strengthening parenting skills, thus preventing problems in child development(22).

Explanations for the low observed effectiveness might focus on the following factors: a) The expectations of social protection during childhood, with respect to the program that has been studied, were too ambitious for an implementation that, per se, is extremely complex given the existing conditions of vulnerability. b) The policy has not worked effectively because of weaknesses in its implementation and the traditional culture concerning health, which has not transcended the biomedical approach; consequently, health professionals would not be responsive to addressing the complexity of social contexts ${ }^{(22)}$. c) The reviewed literature states that the current focus is not centered on the social determinants and rights in health practice, which would allow for the promotion of relevant and timely management(22-23). The low perception of the social vulnerability of the dyad by professional midwives and nurses is a difficulty that limits application of the determinants and guaranteed social rights(22). d) The presence of a segmented and fragmented health practice and operational management, both in health programs and social programs, limits the development of comprehensive solutions in which coordination, cooperation, and collaboration among the social sectors are essential(2,19,22,24). The literature indicates that fragmentation causes ineffectiveness because of the poor linkage between the health and social systems $^{(19,24)}$.

Health policy states that changes are required in the "how, with what, and with whom" patterns and processes because the current scenarios reveal deep and complex social changes that are creating a growing social vulnerability and demand for social and health services ${ }^{(2,25)}$. Overcoming this situation is difficult because the best practices for integrated management are achieved through joint activities and close relationships between disciplines, professions, departments, institutions, and organizations ${ }^{(19,23)}$. Thus, the ambivalence of responsibilities and institutional segmentation in implementing social protection policy can be overcome ${ }^{(20,22)}$.

\section{Conclusion}

The data obtained and the conceptual background allow for the conclusion that, to achieve a greater effectiveness of the comprehensive protection policies that compensate for social inequalities and overcome health disparities during sensitive periods such as maternity and childhood, it is necessary to render social vulnerability visible to perform the actions that facilitate the personal and social development of children and improve the parenting skills and resilience of the primary caregivers.

The results revealed a group of mothers and children in the presence of adverse social determinants and limited access to social benefits - a fact that constitutes a difficulty in promoting safe motherhood, healthy upbringing, and comprehensive development of the infant. This idea deserves consideration regarding the relevance of the role of nursing in health care as a social practice, specifically in primary health care, which is a strategic space for the social and ethical commitment to lead the supervision and monitoring of access to the benefits of social policies. Once this practice is in effect, progress will be made in reducing the gaps and inequalities in the construction of the foundations for lifelong health. 


\section{References}

1. Ley 20379/ 2009 de 12 de septiembre (CH). Sistema intersectorial de protección social e institucionaliza el subsistema de protección integral a la infancia "Chile Crece Contigo". Biblioteca del Congreso Nacional de Chile. [acesso 11 nov 2011]. Disponível em: http://www. leychile.cl/Navegar?idNorma $=1006044$

2. Figueiredo GLA, Mello DF de. Child health care in Brazil: aspects of program vulnerability and human rights. Rev. Latino-Am. Enfermagem. 2007; 15(6):1171-6.

3. Gómez E, Muñoz M, Santelices M. Efectividad de las Intervenciones en Apego con Infancia Vulnerada y en Riesgo Social: Un Desafío Prioritario para Chile. Terapia Psicol. 2008;26(2):241-51.

4. Rojas MG, Fritsch R, Guajardo V, Rojas F, Barroilhet $\mathrm{S}$, Jadresic E. Caracterización de madres deprimidas en el posparto. Rev Méd Chile. 2010;138:536-42.

5. Arcos E, Muñoz LA, Sánchez X, Vollrath A, Latorre

C, Bonatti $C$, et al. Vulnerabilidad social en mujeres embarazadas de una comuna de la Región Metropolitana. Rev Méd Chile. 2011;139:739-47.

6. Rondero Hernandez V, Montana S, Clarke K. Child Health Inequality: Framing a Social Work Response. Health \& Social Work. 2010;35(4):291-301.

7. Organización Mundial de la Salud. Subsanar las desigualdades en una generación. Alcanzar la equidad sanitaria actuando sobre los determinantes sociales de la salud, OMS 2008. [acesso 10 jan 2010]. Disponivel em: http://www.who.int/

8. Bambra C. Health inequalities and welfare state regimes: theoretical insights on a public health 'puzzle'. J Epidemiol Community Health. 2011;65:740-5.

9. Frenz P, González C. Aplicación de una aproximación metodológica simple para el análisis de las desigualdades: El caso de la mortalidad infantil en Chile. Rev Méd Chile. 2010;138:1157-64.

10. Puyol Á. Ética, equidad y determinantes sociales de la salud. Gac Sanit [periódico na Internet]. 2012; 26(2): 178-81, [acesso 04 mar 2013]. Disponivel em: http:// scielo.isciii.es/scielo.php?script=sci_arttext\&pid=S021391112012000200016\&lng=es.

11. Pathak S, David Low M, Franzini L, Swint MJ. A Review of Canadian Policy on Social Determinants of Health. Eur Stud Rev. 2012,4(4):8-22.

12. Schofield T. Health inequity and its social determinants: A sociological commentary. Health Sociol Rev. 2007;16:105-14.
13. Figuereido MC, Santos RM, Leite JL. Enfermagem como prática social: um exercício de reflexão. Rev Bras Enferm. 2008;61(6):904-8.

14. Mannheimer LN, Lehto J, Ostlin P. Window of opportunity for intersectoral health policy in Sweden open, half-open or half-shut? Health Promotion Int. 2007;22(4):307-15.

15. Grugel J. Children's rights and children's welfare after the Convention on the Rights of the Child. Progress Development Studies [periódico na Internet]. 2013;13(1):19-30, [acesso 4 mar 2013]. Disponivel em: pdj.sagepub.com/content/13/1/19.abstract

16. Barros S, Ferreira M, Aranha A. Práticas innovadoras para o cuidado em saúde. Rev Esc Enferm USP. 2007;41:815-9.

17. Bedregal P, González P, Kotliarenco MA, Raczynski D. Chile Lineamientos de política para la primera infancia (menor de 4 años). Banco Interamericano de Desarrollo y UNICEF 2007. [acesso 10 jan 2010]. Disponivel em: http:/www.unicef.cl/archivos documento/238/estudio bid Final.pdf

18. Small R, Taft A, Brown S. The power of social connection and support in improving health: lessons from social support interventions with childbearing women. BMC Public Health [periódico na Internet]. 2011; 11 Suppl 5S4, [acesso 15 fev 2013]. Disponivel em: http:// www.biomedcentral.com/1471-2458/11/S5/S4

19. Mistry K, Minkovitz C, Riley A, Johnson S, Grason H, Guyer B, et al. A New Framework for Childhood Health Promotion: The Role of Policies and Programs in Building Capacity and Foundations of Early Childhood Health. Am J Public Health. 2012;102(9):1688-96.

20. Schmied V, Mills A, Kruske S, Kemp L, Fowler C, Homer $\mathrm{C}$. The nature and impact of collaboration and integrated service delivery for pregnant women, children and families. J Clin Nurs. [periódico na Internet]. 2010; 19(23/24):3516-26 [acesso 14 fev 2013]. Disponível em: http://www.biomedcentral.com/1471-2296/14/2

21. Egry E, Fonseca RM, Oliveira MA, Bertolozzi MR, Takahashi R, Ciosak I, et al . Políticas e práticas de saúde rumo à equidade: uma abordagem geral. Rev Esc Enferm USP. 2007;41(spe):762-4.

22. Moraes J, Cabral I. The social network of children with special health care needs in the (in) visibility of nursing care. Rev. Latino-Am. Enfermagem. 2012;20(2):282-8.

23. Organización Panamericana de la Salud / Organización Mundial de la Salud. La renovación de la atención primaria en las Américas. Edition OPS/OMS; 2007. [acesso $11 \mathrm{dez}$ 2010]. Disponivel em: http:// www.paho.org/spanish/AD/THS/OS/APS_spa.pdf 
24. Stange K. The problem of fragmentation and the need for integrative solutions. Annals Family Medicine. 2009;7(2):100-3.

25. Ministerio de Salud de Chile. Objetivos nacionales de salud para la década 2010-2020. MINSAL 2010. [acesso 13 jan 2011]. Disponivel em: http://www.equidad.cl/ biblioteca/informes/1objetivos.pdf 